\title{
Measuring Fluorescent Dye in the Bubbly and Sediment-Laden Surfzone
}

\author{
David B. Clark • Falk Feddersen • \\ Melissa M. Omand • R. T. Guza
}

Received: 25 September 2008 / Accepted: 10 February 2009 / Published online: 16 April 2009

(C) The Author(s) 2009. This article is published with open access at Springerlink.com

\begin{abstract}
Decisions about recreational beach closures would be enhanced if better estimates of surfzone contaminant transport and dilution were available. In situ methods for measuring fluorescent Rhodamine WT dye tracer in the surfzone are presented, increasing the temporal and spatial resolution over previous surfzone techniques. Bubbles and sand suspended by breaking waves in the surfzone interfere with in situ optical fluorometer dye measurements, increasing the lower bound for dye detection $(\approx 1 \mathrm{ppb})$ and reducing (quenching) measured dye concentrations. Simultaneous turbidity measurements are used to estimate the level of bubble and sand interference and correct dye estimates. After correction, root-mean-square dye concentration errors are estimated to be $<5 \%$ of dye concentration magnitude, thus demonstrating the viability of in situ surfzone fluorescent dye measurements. The surfzone techniques developed here may be applicable to other environments with high bubble and sand concentrations (e.g., cascading rivers and streams).
\end{abstract}

D. B. Clark $(\varangle) \cdot$ F. Feddersen ·

M. M. Omand · R. T. Guza

Scripps Institution of Oceanography, UCSD,

9500 Gilman Dr., mail code 0209, La Jolla, CA

92093-0209, USA

e-mail: clark@coast.ucsd.edu
Keywords Surfzone - Mixing • Dispersion • Fluorometer $\cdot$ Turbidity $\cdot$ Fluorescent dye measurement

\section{Introduction}

Surfzone dispersion is important to many biological and physical processes, including the dilution of contaminated runoff (e.g., Boehm 2003; Grant et al. 2005), phytoplankton transport (e.g., Campbell and Bate 1988), and larval recruitment (e.g., Denny and Shibata 1989). However, few surfzone tracer dispersion studies have been conducted, and measurement techniques are less advanced than those used further offshore. As a result, surfzone tracer dispersion is poorly understood. Increased knowledge of transport and dilution in the surfzone would enable beach managers to better minimize public exposure to shoreline pollution.

Fluorescent dye (e.g., Rhodamine WT, or fluorescein), optically measured with a fluorometer, is commonly used to study tracer (i.e., pollutant) dispersion in both marine (e.g., Okubo 1971) and freshwater (e.g., Csanady 1963) environments. Dye measurements are used to estimate eddy diffusivities and scale dependence (e.g., Okubo 1971; Murthy 1976; Fong and Stacey 2003), tracer transport (e.g., Houghton 1997; Tilburg et al. 2007), and other quantities. The observations of 
diffusion and mixing can be used to calibrate numerical models.

Ideally, accepted in situ techniques using flowthrough (e.g., Pritchard and Carpenter 1960) or open-face (e.g., Ledwell et al. 2004) fluorometers could be adapted for surfzone use. However, surfzone waves and strong currents can damage instrumentation, hamper deployment, and render many oceanographic instruments and platforms (i.e., boats) unusable. Breaking waves intermittently suspend optically interfering bubbles (e.g., Deane 1997) and sediment (e.g., Brenninkmeyer 1976; Yu et al. 1993), creating highly variable turbidity.

Measured dye fluorescence is altered by many factors, including background fluorescence (Pritchard 1979), temperature, and suspended sediment (Smart and Laidlaw 1977). Suspended sediment increases apparent background fluorescence without dye in the water and reduces (quenches) concentration estimates when dye is present. However, the effect of suspended sediment on dye estimates varies with sediment type, color, and concentration (Smart and Laidlaw 1977), and the effect of suspended sand in the surfzone is unknown. The effect of surfzone bubbles on in situ dye measurements is also unknown. Dye mass can also be lost to photochemical decay (e.g., Suijlen and Buyse 1994), adsorption (e.g., Talbot and Boon 1975), and other factors (e.g., Smart and Laidlaw 1977), but these processes are not expected to be significant over the few-hour duration of most surfzone dispersion studies.

Previous surfzone dye measurements have been limited to bottle samples taken either at the shoreline or near the visually estimated center of a spreading dye patch (Harris et al. 1963; Inman et al. 1971; Clarke et al. 2007). While simple and inexpensive, the number and distribution of samples has been severely limited, with maximum rates up to two bottle samples per minute (Clarke et al. 2007), and a maximum of four simultaneous locations over several hours (Harris et al. 1963). These studies provided important initial estimates of surfzone dispersion but could not resolve cross-shore dye structure and used few (or single) dye patch or plume realizations. In situ fluorometers allow for higher-frequency dye measurements, but have not been implemented in the surfzone, possibly because of concerns that suspended bubbles and sand would degrade instrument performance.

Instruments suitable for in situ surfzone measurement of fluorescent Rhodamine WT dye are discussed in Section 2, along with possible mechanisms causing high errors in some instruments. The specific instrumentation used here (Section 3) and testing procedures (Section 4) are described. The effects of surfzone bubbles and sand on in situ Rhodamine WT measurements are characterized, and results are given in Section 5. Errors in in situ surfzone fluorescence are estimated, recommendations are made for error reduction, and example field applications are given in Section 6. Details of mixing and delay time within the mobile flow-through fluorometer system and estimates of effective spatial resolution are given in the Appendix.

\section{Considerations for in situ Surfzone Rhodamine WT Measurement}

Many commercial fluorometers are available. Two widely used, open-face-type fluorometers (WET Labs ECO Triplet and Turner SCUFA) that measure Rhodamine WT dye fluorescence $D$ and turbidity $\tau$ were tested side-by-side in a natural surfzone without dye in the water to determine the instruments' responses to suspended bubbles and sand from breaking waves. Light emitted near the dye excitation peak is fluoresced at a slightly longer wavelength (e.g., Guibault 1990). The intensity of the fluoresced light is detected at an angle to the excitation beam (scattering angle) and used to determine dye concentration (Fig. 1). The WET Labs ECO Triplet measures $D$ (0.1-400 ppb range) with $530 \mathrm{~nm}$ [30 nm full width half max (FWHM)] wavelength excitation, and $570 \mathrm{~nm}$ fluorescence detection (35 nm FWHM), and measures $\tau$ (0.03-100 ntu range) at $660 \mathrm{~nm}$ wavelength. ECO Triplet $D$ and $\tau$ both use $117^{\circ}$ scattering angles. The Turner SCUFA measures $D(0.04-400$ ppb range) with $530 \mathrm{~nm}$ (40 nm FWHM) wavelength excitation, and $600 \mathrm{~nm}$ (40 nm FWHM) fluorescence detection, and measures $\tau\left(0.1-400 \mathrm{ntu}^{*}\right.$ range) at $530 \mathrm{~nm}$. SCUFA $D$ and $\tau$ both use $90^{\circ}$ scattering 


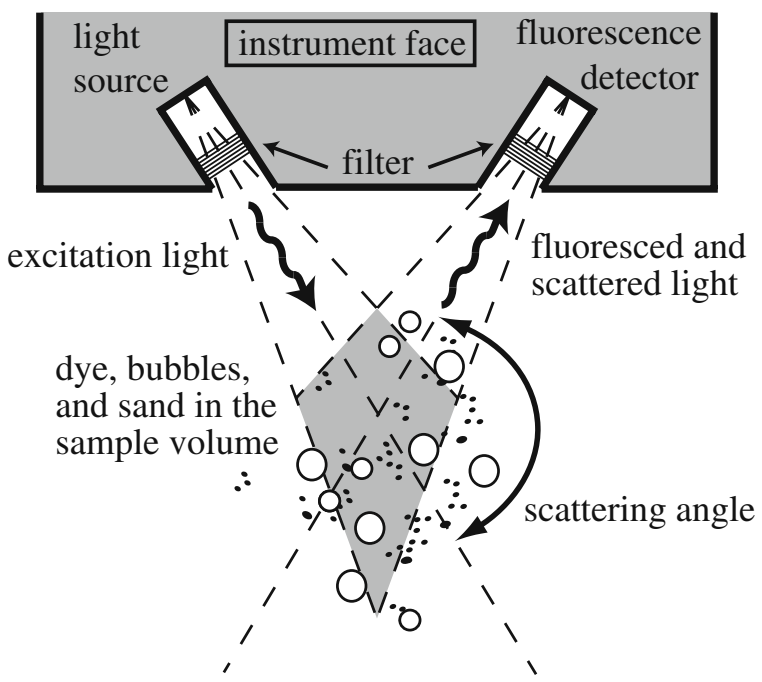

Fig. 1 Schematic of fluorometer optics (ECO Triplet example). Light emitted near the excitation peak of Rhodamine WT is fluoresced by the dye at a longer wavelength and measured by the detector. When dye concentrations are low, bubbles and sand in the sample volume (center shaded region) scatter excitation light from the instrument towards the dye fluorescence detector. Overlap between the instrument excitation spectrum and the fluorescence detection spectrum allows backscattered excitation light to be falsely interpreted as an elevated dye concentration in the sample volume. When dye concentrations are not low, bubbles and sand reduce the amount of fluoresced light reaching the detector, and measured dye concentrations are reduced. Bubbles and sand also backscatter light from the turbidity light source into the turbidity detector (not shown), increasing measured $\tau$

angles. ECO Triplet and SCUFA $\tau$, with units ntu and $n^{*} u^{*}$, respectively, are similar but not equivalent due to instrumental differences (Section 3.2).

The instruments were mounted $1 \mathrm{~m}$ apart, so they were close enough to measure similar turbidities but far enough apart to eliminate interference. Both the ECO Triplet (Fig. 2a) and the SCUFA (Fig. 2b) recorded spurious dye measurements (nonzero dye measurements when no dye is present) in response to $\tau$ from surfzone bubbles and sand. The ECO Triplet recorded very little spurious dye $(<0.8 \mathrm{ppb})$, while the SCUFA recorded large spurious dye measurements (up to $17 \mathrm{ppb}$ ) that were highly correlated with turbidity $\tau$.

The SCUFA and ECO Triplet measure Rhodamine WT fluorescence with different optical elements and angles. Ideally, narrow-banded, nonoverlapping optical filters on the source and detection elements prevent excitation light from being detected as dye. However, nonideal optical filters allow excitation light, backscattered off bubbles and sand (Fig. 1), to pass through the detection filter and to be measured as elevated dye concentrations. The SCUFA optical filters have a slightly wider pass-band than the ECO Triplet, possibly increasing SCUFA spurious dye measurements. However, the SCUFA filter centers are also $10 \mathrm{~nm}$ further apart than the ECO Triplet, slightly reducing this effect. The intensity of light scattered by surfzone bubbles and sand increases with a reduction in scattering angle (Zege et al. 2006). Therefore, the smaller SCUFA scattering angle increases the excitation light incident on the detection filter, enhancing spurious dye measurements.

Although the SCUFA accurately measures Rhodamine WT in many environments, the combined effects of filters and scattering angle make
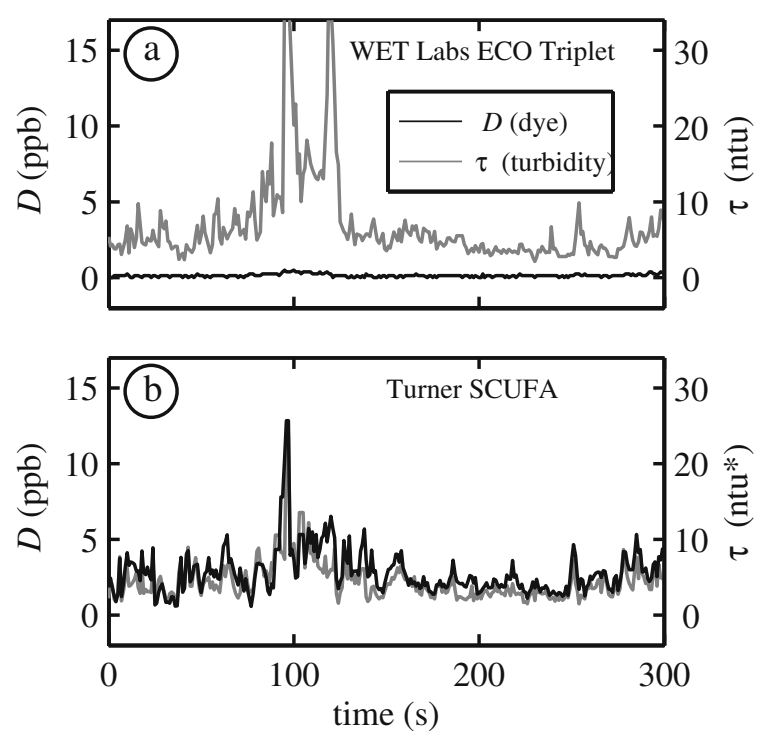

Fig. 2 Field measurements of spurious $D$ (black) and $\tau$ (gray) vs time with no dye in the water for a WET Labs ECO Triplet and $\mathbf{b}$ Turner SCUFA. The instruments were deployed midsurfzone, $0.5 \mathrm{~m}$ above the seabed in $1 \mathrm{~m}$ depth, and separated $1 \mathrm{~m}$ in the alongshore at Scripps Beach, CA, with small spilling waves. Seaward of the surfzone, significant wave height was $0.5 \mathrm{~m}$ and peak period was $15 \mathrm{~s}$. Note turbidity units (ntu, ntu*) are similar but not equivalent due to instrumental differences (Section 3.2) 
the SCUFA dye estimate more sensitive to surfzone bubbles and sand (spurious dye values sometimes reached $80 \mathrm{ppb}$, not shown) than the ECO Triplet. Further testing to determine the effect of surfzone bubbles and sand on ECO Triplet dye measurements is described below (Section 5).

\section{Surfzone Dye Fluorescence Instrumentation}

In situ open-face-type (frame-mounted, fixed location) and flow-through-type (mobile, jet-skimounted, Fig. 3) fluorometer systems were used to measure Rhodamine WT dye concentration $(D)$ in the surfzone. Fixed-location fluorometers provide much higher temporal resolution and longer sampling periods than previous hand-filled bottle methods, but extensive spatial coverage is precluded by cost and logistics. Increased spatial coverage is provided by a jet-ski-mounted fluorometer system. The jet ski allows fast repeated cross- and alongshore transects though the surfzone where traditional boats and submersibles cannot go. Simultaneous turbidity $(\tau)$ measurements are used to estimate relative bubble and sand interference in the instrument sample volume and to correct estimates of $D$. These instruments can also be used to measure surfzone chlorophyll-a, but the methodology differs from that of dye (Omand et al. 2009).

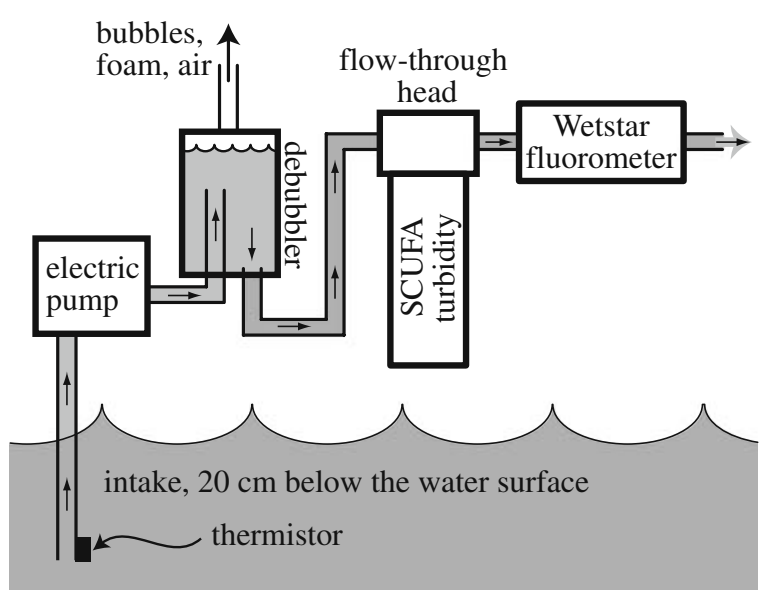

Fig. 3 Schematic of jet ski mounted WS flow-through system (not to scale)
WET Labs ECO Triplet open-face-type fluorometers (hereafter ET) were used to measure dye concentration $D$ and backscatter turbidity $\tau$ (see Section 2 for specifications), and were framemounted at fixed locations in the field. The ETs averaged $8 \mathrm{~Hz}$ data to yield sampling rates of $0.89 \mathrm{~Hz}$ in the laboratory and $0.23 \mathrm{~Hz}$ in the field.

The jet-ski-mounted, flow-through fluorometer/turbidity sensor system (hereafter WS) consisted of a WET Labs Wetstar fluorometer (470 nm excitation wavelength, $570 \mathrm{~nm}$ fluorescence detection, 0.11-400-ppb range) and a Turner SCUFA turbidity sensor (see Section 2 for specifications) with flow-through cap. Although the SCUFA is capable of measuring both fluorescence and turbidity (Section 2), the surfzone fluorescence signal was noisy (Fig. 2). Here, the SCUFA (robust enough for surfzone conditions) is used only for its flow-through turbidity measurement. Water, drawn through the jet-ski-mounted intake boom from $20 \mathrm{~cm}$ below the surface with an electric pump, passes through a debubbler, the SCUFA turbidity sensor, and, finally, the Wetstar fluorometer (Fig. 3). The debubbler (a small 200-ml chamber) allows air to escape from the top and water to flow out of the bottom, reducing the number of large bubbles entering the optical instruments. The flow-through system hoses and debubbler (Fig. 3) smooth sharp gradients in dye occurring over times less than $2.4 \mathrm{~s}$, and delay dye measurements relative to GPS positions (Appendix). Dye fluorescence $D$, turbidity $\tau$, water temperature (measured at the end of the intake boom), and GPS position are sampled at $5 \mathrm{~Hz}$. Data are both logged onboard and transmitted to a shore station, allowing realtime analysis and adaptive sampling. A handlebarmounted screen displays real-time data and a local map of position, allowing repeated sampling of predetermined transects.

\subsection{Fluorometer Calibrations}

Fluorometers were calibrated at four temperatures $\left(7-24{ }^{\circ} \mathrm{C}\right.$ range) using nine known concentrations of Rhodamine WT (0-400-ppb range) in filtered (to remove particles) seawater. Salinity, alkalinity, and $\mathrm{pH}$ all weakly affect dye fluorescence (Feuerstein and Selleck 1963; Smart and 


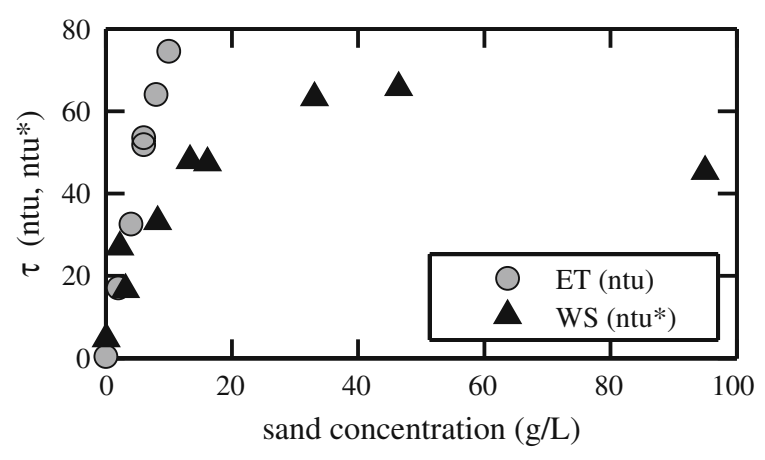

Fig. 4 Laboratory averaged turbidity $\tau$ vs sand concentration for ET (gray circles) and WS (black triangles) using Scripps Beach (La Jolla, CA) sand. For the open-face ET, known amounts of sand were completely suspended by vigorous stirring in a laboratory tank, and turbidity was averaged over $2 \mathrm{~min}$. For the flow-through WS, sand-laden water was drawn into the system, and the average dried sand concentrations were measured from discharge water

Laidlaw 1977; Stanbro and Pyrch 1979); thus, calibrations were always conducted in seawater. Dye calibrations were found to be within $15 \%$ of the

ET

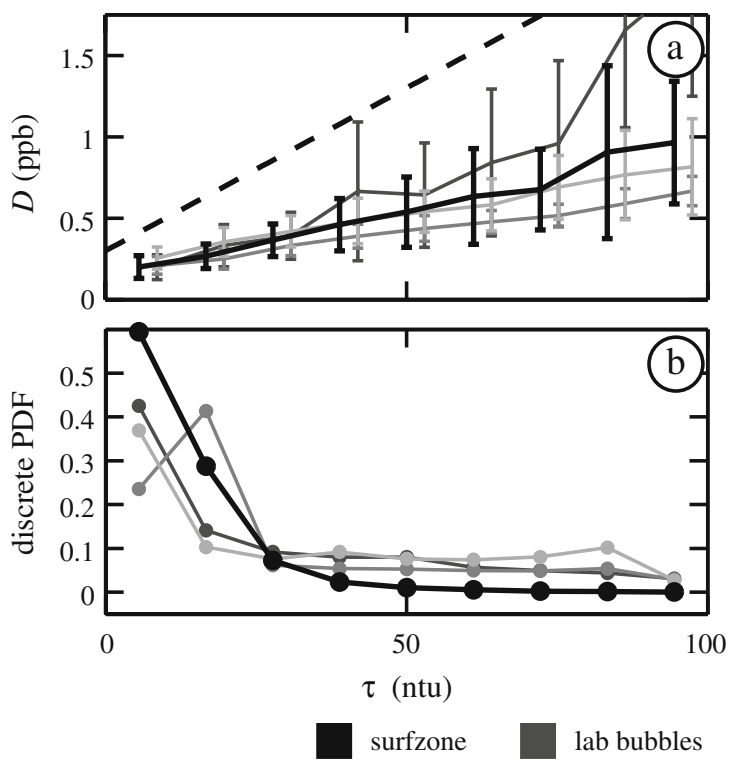

Fig. 5 Field and laboratory results without dye in the water for (left panels) ET and (right panels) WS. a, c Spurious $D$ vs $\tau$ (solid curves), and $D_{\text {low }}$ fit (dashed curve) from Eq. 1. b, $\mathbf{d}$ Discrete probability density functions $(P D F)$ of $\tau$ corresponding to top panels. $D$ is given as binned means, with vertical bars indicating \pm one STD. ET field data (solid black curves) combine several cross-shore locations factory calibrations. ET calibrations were slightly nonlinear above $100 \mathrm{ppb}$, and Wetstar calibrations were linear up to $400 \mathrm{ppb}$. Calibrations before and after the field deployment were similar. Temperature dependence followed Smart and Laidlaw (1977), $D_{T_{0}}=D_{T} \exp \left[0.027\left(T-T_{0}\right)\right]$, where $D_{T_{0}}$ is the dye fluorescence normalized to a reference temperature $T_{0}\left({ }^{\circ} \mathrm{C}\right)$, and $D_{T}$ is the dye fluorescence at the in situ temperature $T\left({ }^{\circ} \mathrm{C}\right)$. Factory turbidity calibrations were used for both the ET and WS.

\subsection{Turbidity Measurements}

Turbidity $\tau$ measured with the ET (ntu) and the SCUFA (ntu*) are not equivalent because the backscatter wavelengths and angles are different (Section 2). In laboratory experiments using Scripps Beach sand suspended in seawater (Fig. 4), SCUFA and ET $\tau$ were similar for sand concentrations $<8 \mathrm{gL}^{-1}\left(<30 \mathrm{ntu}, \mathrm{ntu}^{*}\right)$. However, above $8 \mathrm{gL}^{-1}$, the SCUFA $\tau$ was less

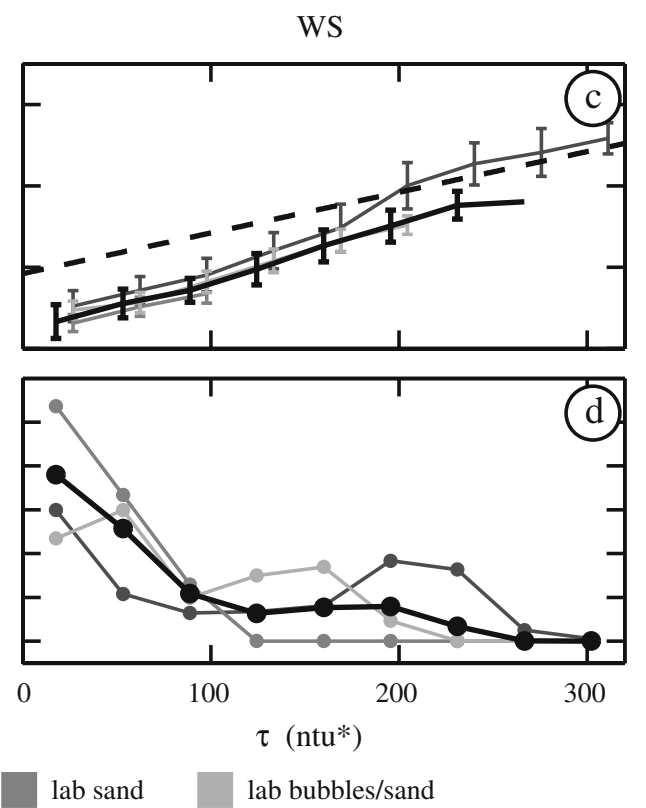

within the surfzone, and field data for the WS combine multiple cross-shore transects. Laboratory data are given for $\tau$ from bubbles, from sand, and from bubbles and sand combined (see legend). Between 1,200 (lab) and 28,000 (field) samples are used to construct ET curves, and 1,180 (field) to 5,398 (lab) samples for each WS curve 
responsive to sand than the ET. The SCUFA $\tau$ sensor saturates near $75 \mathrm{ntu}^{*}$, at sand concentrations $>20 \mathrm{~g} \mathrm{~L}^{-1}$ that are not expected above the bottom boundary layer in the surfzone. Additional tests (Fig. 5) show that SCUFA $\tau>75 \mathrm{ntu}^{*}$ can be produced by bubbles or a combination of bubbles and sand, but not by sand alone. SCUFA $\tau$, well beyond the recommended $100 \mathrm{ntu}^{*}$ upper limit (Turner Designs SCUFA manual, revision 2.1), are used because they prove useful for error estimation and dye correction in the WS instrument package (Section 6). The $\tau$ response to bubble void fraction was not measured.

\section{Instrument Testing Methods}

The effects of surfzone-bubble and sand-induced turbidity $\tau$ on dye measurements $D$ were observed both with and without dye in the water. Experiments without dye were conducted in both the field (surfzone) and the laboratory. However, controlled dye concentrations could not be produced in the field, so tests with known (non-zero) dye concentrations were performed in the lab where $\tau$ levels were varied by altering the amount of suspended bubbles and sand. To apply laboratorybased results to the field, it is assumed that natural surfzone $\tau$ over a sand bottom is primarily caused by bubbles and sand (i.e., not from mud, organic matter, etc.).

\subsection{Field Methods}

ET and WS instruments were tested over several days in the surfzone at Huntington Beach, California, where significant wave height was about $1 \mathrm{~m}$, peak periods ranged from 14 to $16 \mathrm{~s}$, and hourly surfzone averaged alongshore currents reached $0.5 \mathrm{~m} \mathrm{~s}^{-1}$. Huntington Beach sand is a tan, medium-grained quartz typical of the Southern California coast. Four ETs were deployed in various cross-shore locations between the shoreline and $4 \mathrm{~m}$ mean water depth. The ETs were mounted nominally $0.5 \mathrm{~m}$ above the bed with the sensor facing downward at 30 degrees from vertical. Collocated temperature measurements were used for ET dye calibration (Section 3.1). The jet-ski-mounted WS was driven on $\approx 200$-m-long cross-shore transects from seaward of the surfzone towards the shore (inbound transect) until the jet ski turned around near the shoreline $(\approx 0.5 \mathrm{~m}$ water depth) and returned offshore (outbound transect). WS field data were corrected for delay time (relative to GPS positions) within the flowthrough system (Appendix).

\subsection{Laboratory Methods}

Laboratory experiments with and without dye in the water were conducted for both the openfaced ET and the flow-through WS system. Black (to reduce reflected light) containers were filled with 151 of filtered seawater and five dye concentrations (0-238 ppb). The ET was held in the container at midwater depth $(\approx 15 \mathrm{~cm})$, and for the WS, the intake and discharge hoses were mounted near the bottom of the container. Bubbles $(\approx 0.1-5 \mathrm{~mm}$ diameter $)$, roughly representative of those injected into the surfzone by breaking waves (Deane and Stokes 1999), were added using an aquarium aerator. Scripps Beach sand, a tan, medium-grained quartz, was added by hand. Each system was perturbed with bubbles; then with sand; and, finally, with bubbles and sand combined. Bubbles and sand were suspended by vigorous stirring, allowed to settle, and then the process was repeated. It was unknown if the bubble and sediment size distribution of a stirred laboratory container closely represented that suspended in a natural surfzone. However, the amounts of bubbles and sand in the laboratory were varied so the turbidity range spanned that found in the field.

\section{Results}

\subsection{Field and Laboratory Without Dye}

Field and laboratory data ( $D$ and $\tau$ ) without dye in the water were collected with the ET (Fig. 5a, b) and the WS (Fig. 5c, d) instruments. Spurious dye concentrations $D$ (when no dye is present) increase with turbidity $\tau$ in both field and laboratory measurements, consistent with Smart and Laidlaw (1977). High $\tau$ events are infrequent in the surfzone for both instruments (Fig. 5b, d), 
resulting in low mean spurious $D(0.25 \mathrm{ppb}$ for $\mathrm{ET}$, and $0.39 \mathrm{ppb}$ for WS) in the surfzone.

The standard deviation (STD) of spurious dye measurements (indicated by vertical bars) increases with $\tau$ for the ET (Fig. 5a) but remains nearly constant for the WS (Fig. 5c). ET laboratory $D$ results are similar to the surfzone, where combined bubble/sand results are the closest to the field (Fig. 5a). WS lab results are also similar to the surfzone (Fig. 5c), but only the bubbleperturbed test produced the full range of observed surfzone turbidity (because of the strongly nonlinear $\tau$ response to sand, Section 3.2).

Spurious dye measurements are small; however, the integral over many spurious measurements in time (ET) or space (WS) can effect dye concentration statistics (e.g., total dye mass, dye patch/plume width). For example, if the WS was driven on a cross-shore transect without dye in the water, the inclusion of spurious dye measurements would suggest that dye, and the resulting

ET
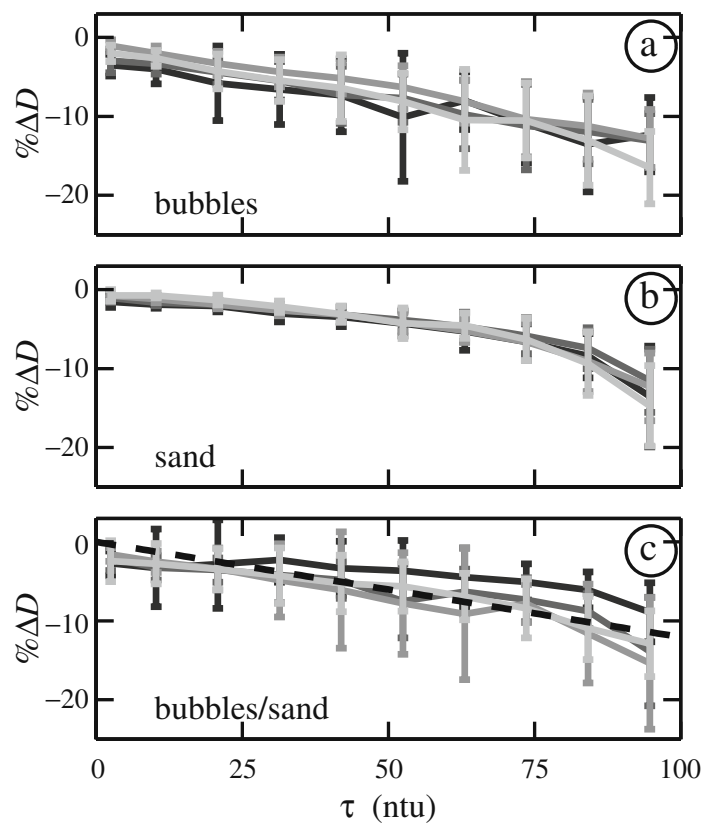

Fig. 6 Percent change in measured dye \% $\Delta D$ (Eq. 2) vs $\tau$ from a, d bubbles; b, e sand; and c, f bubbles and sand combined, for (left panels) ET and (right panels) WS with four dye concentrations in the lab (see legend). $\% \Delta D$ are given as binned means, with vertical plume/patch width, spanned the entire transect. To remove spurious dye measurements for both instruments in the surfzone, a lower bound for dye detection $D_{\text {low }}$ is estimated by a fit to $D>99 \%$ of the spurious surfzone $D$ in each bin vs binned $\tau$. The disadvantage of this approach is that it sets a lower limit on measurable dye concentration and the resultant size and duration that a dye patch/plume can be observed. However, it is suggested that $D$ below $D_{\text {low }}$ be set equal to zero to avoid biasing dye statistics. The fit (Fig. 5a, c, dashed black line) to surfzone field data without dye for each instrument, respectively, is

$D_{\text {low }}=\alpha \tau+C$,

where $\alpha$ and $C$ are fit constants and $D_{\text {low }}$ is in ppb. For the ET, $\alpha=0.02 \mathrm{ppb} \cdot \mathrm{ntu}^{-1}$, and $C=$ $0.3 \mathrm{ppb}$, and for the WS, $\alpha=0.01 \mathrm{ppb} \cdot \mathrm{ntu}^{*-1}$, and $C=0.46 \mathrm{ppb}$.
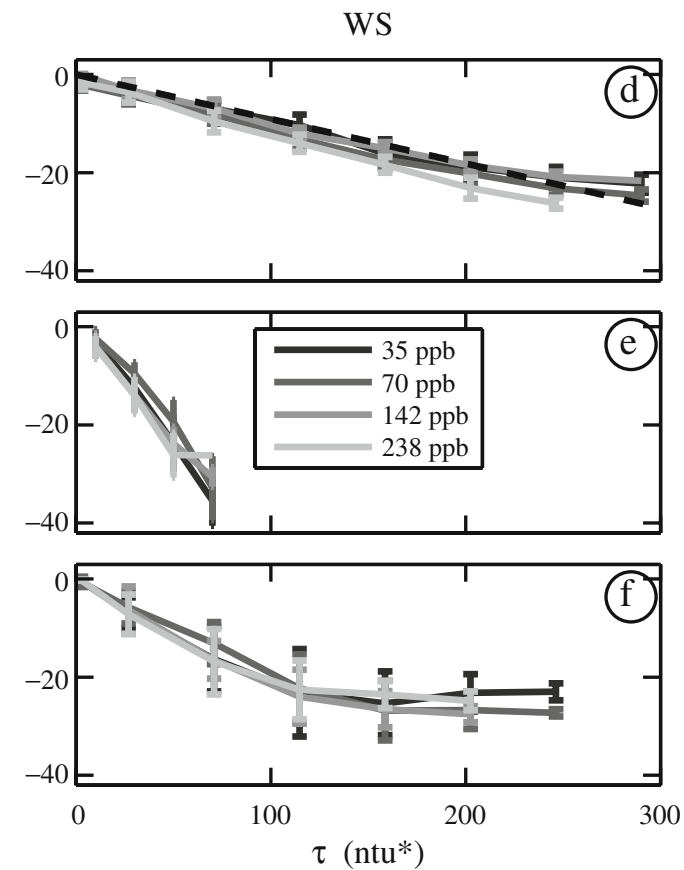

bars indicating \pm one STD. Between 550 and 860 ET and 3,600 and 5,400 WS samples are used to construct each curve. Dashed black lines in c and d show fits (Eq. 5) to binned mean data 


\subsection{Laboratory with Dye}

Four known dye concentrations $\left(D_{0}\right)$ were perturbed with bubbles (Fig. 6a, d), sand (Fig. 6b, e), and a combination of bubbles and sand (Fig. 6c, f) for ET (Fig. 6a-c) and WS (Fig. 6d-f), respectively. Changes in measured dye concentration $D$ are given as percent change $\% \Delta D$ from the unperturbed known $D_{0}$

$\% \Delta D=100\left(D-D_{0}\right) / D_{0}$.

The mean $\% \Delta D$ is almost always negative (i.e., quenching) and is similar for all dye concentrations (curves within each panel of Fig. 6 overlay each other). This concentration-independent $\% \Delta D$ is consistent with Smart and Laidlaw (1977) for $\tau$-induced quenching of Rhodamine WT, but contrasts with the concentration-dependent $\tau$ induced quenching of chlorophyll-a (Omand et al. 2009). The STD (vertical bars) about the mean $\% \Delta D$ increases with $\tau$ for the ET, and to a lesser extent for the WS. The relationship between ET $\% \Delta D$ and $\tau$ is similar for bubbles, sand, and bubbles and sand combined (i.e., curves in all left panels are similar), and the maximum decrease ( $\% \Delta D \approx-20 \%$, binned mean minus one STD) due to $\tau$ occurs at near full-scale turbidity values. However, bubbles affect the WS differently than sand (Fig. 6d, e), with bubbles producing $\tau$ up to $300 \mathrm{ntu}^{*}$ with moderate quenching effects (binned mean $\% \Delta D$ minus one STD as large as $-25 \%$ ), and sand producing $\tau$ up to $75 \mathrm{ntu}^{*}$ with large quenching effects (binned mean $\% \Delta D$ minus one STD as large as $-40 \%)$. The large WS sand-quenching effect at moderate $\tau$ values is consistent with very high sand concentrations (that block fluoresced light) required to approach the $75 \mathrm{ntu}^{*}$ saturation point for sand-induced $\tau$ (Fig. 4).

\section{Dye Measurement Corrections}

Dye measurement errors are reduced by discarding dye data points with turbidity $\tau$ above a threshold, and correcting the remaining dye for $\tau$-induced quenching. ET data were removed when $\tau>90 \mathrm{ntu}$ to exclude the increased scatter in quenching (Fig. 6c) near and beyond the instrument $\tau$ saturation point (100 ntu). WS data were removed when $\tau>300 \mathrm{ntu}^{*}$, the highest labobserved $\tau$ (and, thus, the limit of lab-based $\tau$ correction). The combination of discarding high $\tau$ data and correcting the remaining $D$ for $\tau$-induced quenching is hereafter called correction.

Surfzone fluorometers encounter bubbles and sand suspended by breaking waves and strong currents. The ET turbidity sensor cannot distinguish between bubbles and sand. However, the effects of bubble- and sand-induced $\tau$ on ET dye quenching are similar (Fig. 6a, b), and the curve derived from the combination of bubbles and sand (dashed line in Fig. 6c) is used for ET corrections. In contrast, bubbles- and sand-induced $\tau$ produce very different dye-quenching effects in the WS (Fig. 6d, e), but, as with the ET, the instrument cannot distinguish between $\tau$ from bubbles and $\tau$ from sand. In the present application, the jetski-mounted WS system samples water $20 \mathrm{~cm}$ below the surface where average sand concentrations are expected to rarely exceed $1 \mathrm{~g} \mathrm{~L}^{-1}$ (e.g., Beach and Sternberg 1992; Yu et al. 1993; Beach and Sternberg 1996; Ogston and Sternberg 2002). Even extreme sand concentrations ( $>20 \mathrm{~g} \mathrm{~L}^{-1}$ ) only result in $\tau$ up to $75 \mathrm{ntu}^{*}$ (Fig. 4) with the WS $\tau$ sensor, leaving about one third of the field data with higher $\tau$ than sand alone can produce (Fig. 5d). Therefore, bubbles are assumed to be the $\tau$ source, and WS dye measurement corrections are made using the bubble-quenching curve (Fig. 6d).

The relationship between binned mean $\% \Delta D$ (Eq. 2) and $\tau$ are used to correct for $\tau$-induced dye quenching. The fits to ET bubbles and sand combined (Fig. 6c, dashed black line) and WS bubbles only (Fig. 6d, dashed black line) have the form

$\% \Delta D=100 \beta \tau$.

Substituting Eq. 2 into Eq. 3 yields

$\frac{D-D_{0}}{D_{0}}=\beta \tau$,

where the fit constant is $\beta=1.2 \times 10^{-3} \mathrm{ntu}^{-1}$ (ET) and $\beta=0.91 \times 10^{-3} \mathrm{ntu}^{*-1}$ (WS). Equating $D_{0}$ to corrected dye concentration $D_{\mathrm{c}}$, and $D$ to 

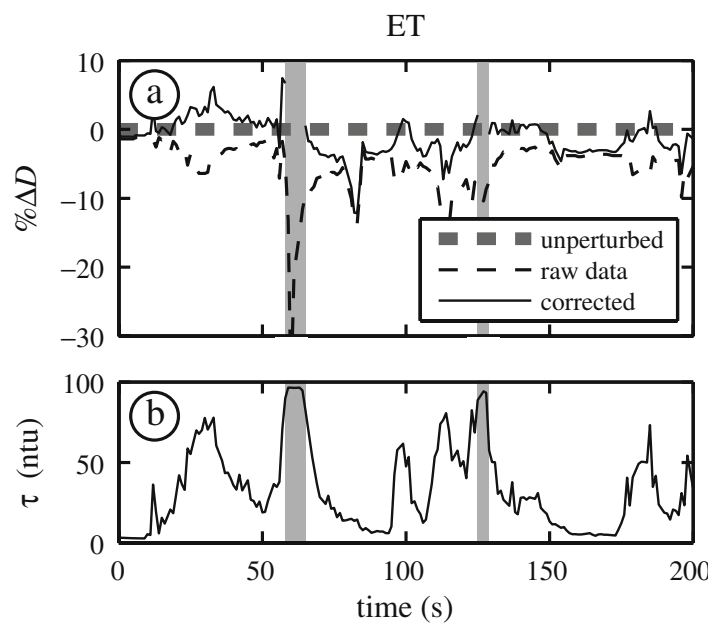

Fig. 7 Laboratory examples of a, $\mathbf{c}$ percent change in raw $\% \Delta D_{\mathrm{r}}$ (dashed black curves) and corrected $\% \Delta D_{\mathrm{c}}$ (with Eq. 5, solid black curves) dye concentration and $\mathbf{b}$, d turbidity $\tau$ vs time, for (left panels) ET and (right panels) WS. Thick dashed gray line is the unperturbed $\% \Delta D=0$.

the raw dye concentration $D_{\mathrm{r}}$, Eq. 4 yields the equation to correct $D_{\mathrm{r}}$ for $\tau$-induced quenching

$D_{\mathrm{c}}=\frac{D_{\mathrm{r}}}{1-\beta \tau}$.

In laboratory tests with known $D_{0}=70 \mathrm{ppb}$ (Fig. 7), the magnitude of raw $\% \Delta D_{\mathrm{r}}$ (Eq. 2) is increased by $\tau$-induced quenching during periods of high turbidity. Corrected dye concentrations $D_{\mathrm{c}}$ are usually more accurate than raw $D_{\mathrm{c}}\left(\left|\% \Delta D_{\mathrm{c}}\right|<\left|\% \Delta D_{\mathrm{r}}\right|\right)$. Occasionally, $D_{\mathrm{r}}$ is quenched when $\tau$ is low (e.g., at $t=80 \mathrm{~s}$, Fig. 7a), and significant errors $(\sim 15 \%)$ remain in corrected $D_{\text {c }}$. Discarding ET measurements with $\tau>$

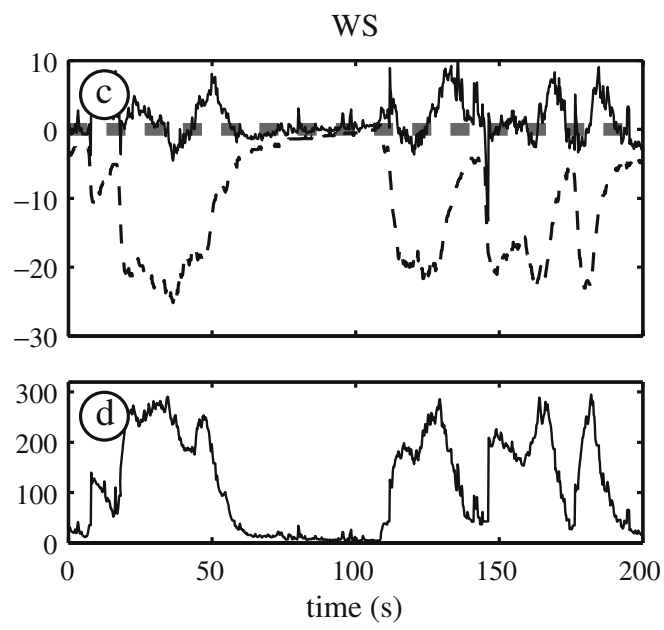

For the ET (WS) seawater with a known $D_{0}=70-\mathrm{ppb}$ dye concentration was perturbed with bubbles and sand (bubbles only). a Light gray vertical bands indicate times when $\tau>90 \mathrm{ntu}$. At $t \approx 60 \mathrm{~s}$, the ET $\tau$ sensor is saturated at $\approx 100 \mathrm{ntu}$

90 ntu (light gray vertical bars) removed the large spike at $t=60 \mathrm{~s}$ (Fig. 7a) when the $\tau$ sensor was saturated. Results are qualitatively similar for other $D_{0}$ (not shown).

Errors in raw $D_{\text {r }}$ and corrected $D_{\text {c }}$ (discarding high $\tau$ data and using Eq. 5) are calculated from laboratory data perturbed with a combination of bubbles and sand (bubbles only) for the ET (WS) with four dye concentrations (Table 1). For both raw and corrected data, percent root-mean-square errors $\% \varepsilon_{\text {rms }}=100 \times\left\langle\left(D_{r, c}-D_{0}\right)^{2}\right\rangle^{1 / 2} / D_{0}$ and mean errors $\% \varepsilon_{\mathrm{m}}=100 \times\left\langle D_{r, c}-D_{0}\right\rangle / D_{0}$ are given (Table 1), where \langle\rangle indicates a time average. Raw percent error magnitudes are independent of

Table 1 Percent errors (rms $\% \varepsilon_{\mathrm{rms}}$, and mean $\% \varepsilon_{\mathrm{m}}$ ) in the laboratory with known dye concentration $D_{0}$ (left column) perturbed with bubbles and sand (ET), and bubbles (WS)

\begin{tabular}{|c|c|c|c|c|c|c|c|c|}
\hline \multirow[t]{3}{*}{$D_{0}(\mathrm{ppb})$} & \multicolumn{4}{|l|}{ ET } & \multicolumn{4}{|l|}{ WS } \\
\hline & \multicolumn{2}{|c|}{$\% \varepsilon_{\text {rms }}$} & \multicolumn{2}{|l|}{$\% \varepsilon_{\mathrm{m}}$} & \multicolumn{2}{|c|}{$\% \varepsilon_{\text {rms }}$} & \multicolumn{2}{|l|}{$\% \varepsilon_{\mathrm{m}}$} \\
\hline & Raw & Corrected & Raw & Corrected & Raw & Corrected & Raw & Corrected \\
\hline 35 & 6.0 & 5.0 & -3.9 & 0.7 & 12.1 & 2.7 & -9.3 & -0.3 \\
\hline 70 & 8.3 & 4.9 & -6.7 & -1.6 & 12.0 & 1.8 & -8.9 & -0.1 \\
\hline 142 & 8.5 & 5.0 & -5.8 & -1.1 & 12.4 & 1.4 & -10.4 & -0.4 \\
\hline 238 & 6.6 & 3.3 & -4.7 & -1.0 & 11.8 & 2.6 & -8.9 & -1.8 \\
\hline
\end{tabular}

$\% \varepsilon_{\mathrm{rms}}$ and $\% \varepsilon_{\mathrm{m}}$ are given for raw data, and data corrected by removing high turbidity (ET $\tau>90 \mathrm{ntu}$, WS $\left.\tau>300 \mathrm{ntu}\right)$ dye measurements and using Eq. 5 

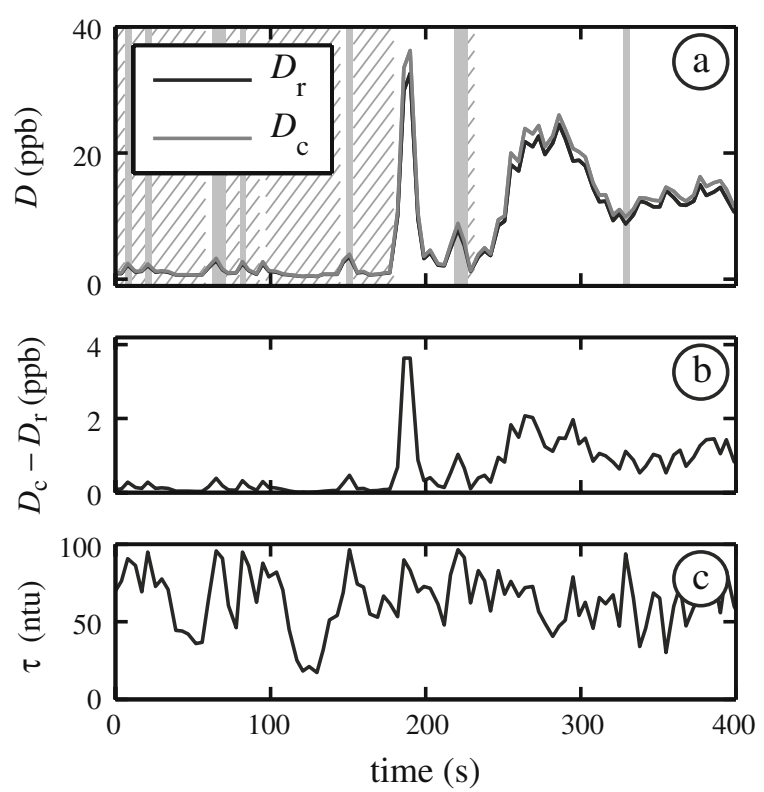

Fig. 8 ET a raw and corrected dye concentration $\left(D_{\mathrm{r}}\right.$, $\left.D_{\mathrm{c}}\right)$, b correction magnitude $\left(D_{\mathrm{c}}-D_{\mathrm{r}}\right)$, and c $\tau$ vs time in the surfzone. The instrument was mounted $65 \mathrm{~m}$ from the shoreline, and $50 \mathrm{~cm}$ above the bottom. A dye patch ( 0.251 of $21 \%$ by weight Rhodamine WT) was released $10 \mathrm{~m}$ alongshore from the ET at $t=150 \mathrm{~s}$. a $D_{\mathrm{c}}$ (gray curve) is estimated from $D_{\mathrm{r}}$ (black curve) and corresponding $\tau$ time series, using (Eq. 5). Light gray vertical bands indicate times when $\tau>90 \mathrm{ntu}$ (data are removed). Light gray hatching indicates times when $D_{\mathrm{r}}<D_{\text {low }}$ (Eq. 1), and $D_{\mathrm{r}, \mathrm{c}}$ should be set to zero

concentration and are, generally, $<9 \%(<13 \%)$ for ET (WS). For both ET and WS, correction reduces $\operatorname{rms}\left(\left|\% \varepsilon_{\mathrm{rms}}\right|<5 \%\right)$ and mean $\left(\left|\% \varepsilon_{\mathrm{m}}\right|<\right.$ $2 \%)$ errors. Error propagation into spatial dye moments is nontrivial and depends on the shape of the dye distribution, how realizations are averaged, and the assumed noise decorrelation scale. However, for a simple Gaussian example with 5\% rms noise and a noise decorrelation scale equal to one STD of the Gaussian itself, the rms error in measured variance is $2 \%$.

Examples of corrections to surfzone dye measurements are shown for ET (Fig. 8) and WS (Fig. 9). ET $\tau$-induced quenching corrections $D_{\mathrm{c}}-D_{\mathrm{r}}$ are small ( $<4 \mathrm{ppb}$, Fig. $\left.8 \mathrm{~b}\right)$ compared to dye variability (Fig. 8a). WS corrections are similarly small ( $<1 \mathrm{ppb}$ on the inbound transect), but they reach $9 \mathrm{ppb}$ on the outbound transect when $\tau$ elevated by bubbly water is drawn into the flow-through system when the jet ski drives over bubble-filled bores (Fig. 10b). On inbound transects, bubbles are reduced by driving just in front of the shoreward traveling bore (Fig. 10a). WScorrected $D_{\mathrm{c}}$ on sequential inbound and outbound transects have closer peak values than $D_{\mathrm{r}}$.

High-turbidity events associated with increased error are less frequent in the field than the lab (Fig. 5b); thus, ET dye measurement errors in the surfzone are expected to be smaller than in the laboratory (Table 1). In contrast, WS field errors may be increased relative to laboratory errors by rare high-concentration sand events that are unaccounted for in lab estimates.

\section{Summary}

Open-face (ET) and flow-through (jet-skimounted WS) Rhodamine WT fluorometers for in situ surfzone sampling were tested. Surfzone
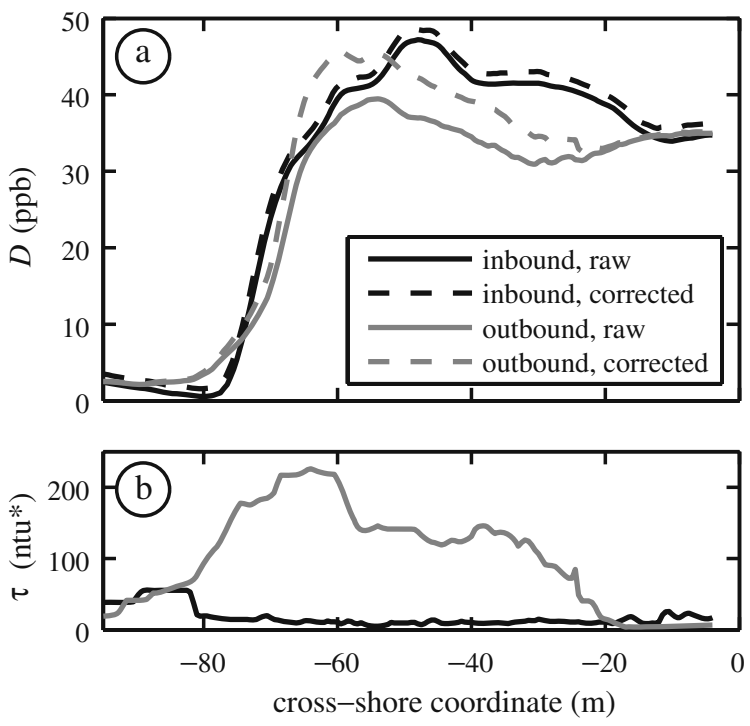

Fig. 9 WS a $D$ and b $\tau$ vs cross-shore coordinate (positive onshore, with shoreline at zero), for a single crossshore transect pair, $575 \mathrm{~m}$ alongshore from the dye source during a continuous release in the surfzone. Inbound and outbound transect raw $D$ and $\tau$, and corrected $D$, are shown (see legend). Inbound corrected dye curve is vertically offset by $+1 \mathrm{ppb}$ for visibility. $D>D_{\text {low }}$, and rootmean-square $D_{\text {low }}$ was 0.56 and $0.62 \mathrm{ppb}$ for inbound and outbound transects, respectively. About $1 \mathrm{~min}$ of data are shown 
Fig. 10 a Inbound and b outbound cross-shore transects through the surfzone with the jet-ski-mounted WS. a Inbound transect bubbles are minimized by driving just in front of a shoreward-traveling bore. b On outbound transects, bubbly water is drawn into the flow-through WS system as the jet ski drives over a bore

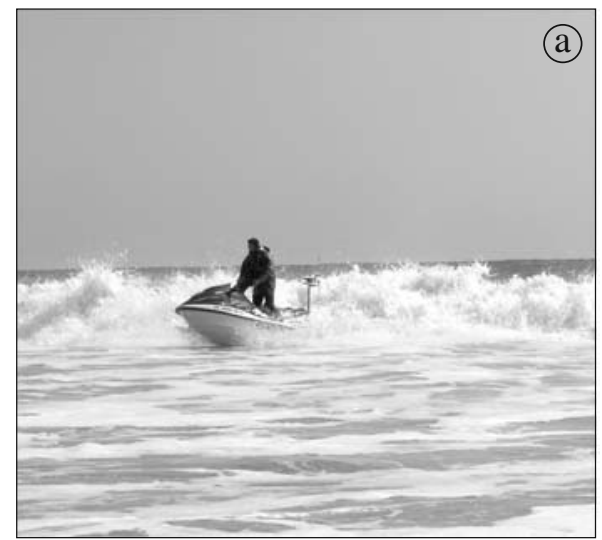

(a)

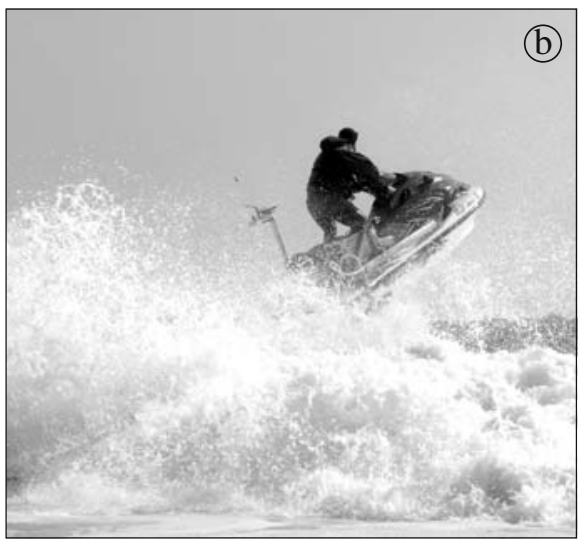

bubbles and sand (measured as turbidity $\tau$ ) interfere with fluorescent dye measurements both raising the lower bound for dye detection $D_{\text {low }}$ (Eq. 1) and reducing (quenching) measured dye fluorescence $D$ (Fig. 6). Laboratory experiments with known dye concentrations $D_{0}$ in seawater were perturbed with bubbles, sand, and bubbles and sand combined to explore the effect of $\tau$ on $D$. The reduction in measured $D$ increases with $\tau$, and the observed relationship is used to correct surfzone dye estimates. Percent root-meansquare $\% \varepsilon_{\text {rms }}$ and mean $\% \varepsilon_{\mathrm{m}}$ errors for the ET and WS are reduced to $<5 \%$ by discarding high- $\tau$ data and using Eq. 5. In situ Rhodamine WT measurements are feasible in the surfzone, allowing comprehensive tracer mixing and transport experiments in this heavily used but poorly understood region of the ocean.

Acknowledgements Brian Woodward, Bill Boyd, Kent Smith, Dennis Darnell, and Ian Nagy designed, built, and operated the jet-ski-mounted instrument package and installed instruments in the field. ONR provided support to design and build the jet-ski-mounted instrument package. Further support was provided by the California Coastal Conservancy, NOAA, California Sea Grant, and NSF. DBC was supported with a NDSEG Fellowship.

Open Access This article is distributed under the terms of the Creative Commons Attribution Noncommercial License which permits any noncommercial use, distribution, and reproduction in any medium, provided the original author(s) and source are credited.

\section{Appendix: Flow-Through Mixing and Delay Time}

Continuously pumped water in the WS flowthrough system (Fig. 3) is mixed (in hoses and the debubbler), smoothing out sharp gradients in dye concentration. In addition, water takes several seconds (delay time) to move through the hoses and debubbler before reaching the fluorometer. This delay time must be accounted for to match GPS positions with dye measurements. Smoothing and delay time are specific to the pump, hoses (length, diameter, and roughness), and debubbler (not commercially available) used in the WS flowthrough system. The specific smoothing and delay time estimates in the WS system are presented here to provide context for the results presented

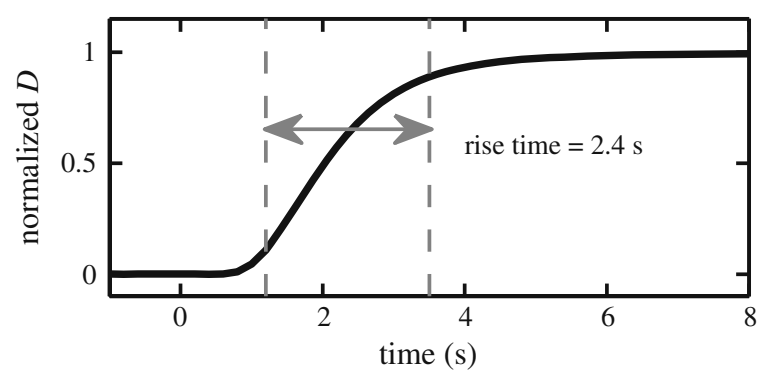

Fig. 11 Mean (over five step functions) time series of normalized WS dye concentration (black curve) in response to a dye step function input. The system output shows a 10$90 \%$ rise time (between dashed gray lines) of $2.4 \mathrm{~s}$, due to mixing in the flow-through system hoses and the debubbler 

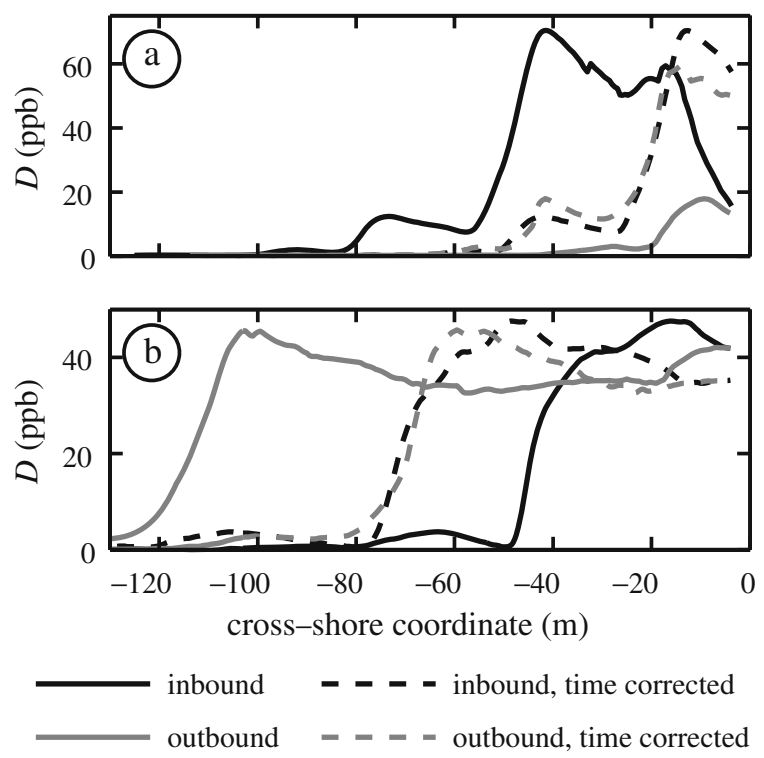

Fig. 12 WS dye $D$ vs cross-shore coordinate (positive onshore, with shoreline at zero), for single inbound (black) and outbound (gray) cross-shore transect pairs, a $50 \mathrm{~m}$ and b $575 \mathrm{~m}$ alongshore from the dye source during a continuous release. Time-corrected inbound and outbound curves (dashed) are similar, suggesting that system delay time in raw data (solid) is accounted for

above and to establish a framework for characterizing similar systems in the future.

Smoothing in the WS flow-through system was estimated with laboratory experiments using step functions of dye (created by switching the intake between water with zero and a known dye concentration with a Y valve, Fig. 11). The 2.4 s 10 $90 \%$ rise time gives the temporal smoothing scale. This smoothing in time gives rise to smoothing in space, which depends on jet ski speed (i.e., $2.4 \mathrm{~s}$ multiplied by jet ski speed). For example, at a typical jet ski speed of $4 \mathrm{~m} \mathrm{~s}^{-1}$ (the linear wave speed in $1.6 \mathrm{~m}$ water depth), the distance between independent samples is about $9.6 \mathrm{~m}$. The WS flow-through system, essentially a low-pass filter, results in smoothing for dye concentration frequencies greater than about $(2.4 \mathrm{~s})^{-1}$ entering the WS system. The severity of the smoothing increases with frequency and is reduced by using slower jet ski speeds (thus reducing frequency). The smoothing magnitude can be estimated from the assumed true dye wavenumber spectrum and the jet ski speed.
The WS flow-through system, essentially a low-pass filter, results in smoothing for dye concentration frequencies greater than about $(2.4 \mathrm{~s})^{-1}$ entering the WS system. The severity of the smoothing increases with frequency and is reduced by using slower jet ski speeds (thus reducing frequency). The smoothing magnitude can be estimated from the assumed true dye wavenumber spectrum and the jet ski speed.

Sequential inbound-outbound transect pairs were used to find WS system delay times by minimizing the difference between the inbound and the outbound cross-shore dye concentrations (similar to Fig. 12). From 64 transect pairs, a delay of $8 \mathrm{~s}$ was the most common value (i.e., the mode), with a mean delay of $8.1 \mathrm{~s}$. The 8 -s value was used to correctly time the WS field data. In examples of WS $D$ vs cross-shore distance, sequential inbound and outbound transects are closer in shape and location after time correction (Fig. 12). The addition of a flow rate sensor is planned to more accurately estimate the delay time. The STD of the field delay times, $\pm 0.84 \mathrm{~s}$, results in spatial uncertainty that depends on jet ski speed. For example, the spatial uncertainty is approximately $\pm 3.3 \mathrm{~m}^{2} 4 \mathrm{~m} \mathrm{~s}^{-1}$ speed.

\section{References}

Beach, R. A., \& Sternberg, R. W. (1992). Suspended sediment transport in the surf zone: Response to incident wave and longshore current interaction. Marine Geology, 108, 275-294.

Beach, R. A., \& Sternberg, R. W. (1996). Suspendedsediment transport in the surf zone: Response to breaking waves. Continental Shelf Research, 16(15), 1989-2003.

Boehm, A. B. (2003). Model of microbial transport and inactivation in the surf zone and application to field measurements of total coliform in Northern Orange County, California. Environmental Science and Technology, 37(24), 5511-5517.

Brenninkmeyer, S. J. B. (1976). In situ measurements of rapidly fluctuating, high sediment concentrations. Marine Geology, 20(2), 117-128.

Campbell, E. E., \& Bate, G. C. (1988). The influence of current direction on longshore distribution of surf phytoplankton. Botanica Marina, 31, 257-262.

Clarke, L. B., Ackerman, D., \& Largier, J., (2007). Dye dispersion in the surfzone: Measurements and simple models. Continental Shelf Research, 27, 650-669. 
Csanady, G. T. (1963). Turbulent diffusion in Lake Huron. Journal of Fluid Mechanics, 17(3), 360-384.

Deane, G. B. (1997). Sound generation and air entrainment by breaking waves in the surf zone. Journal of the Acoustical Society of America, 102(5), 2671-2689.

Deane, G. B., \& Stokes, M. D. (1999). Air entrainment processes and bubble size distributions in the surf zone. Journal of Physical Oceanography, 29, 13931403.

Denny, M. W., \& Shibata, M. F. (1989). Consequences of surf-zone turbulence for settlement and external fertilization. American Naturalist, 134, 859-889.

Feuerstein, D. W., \& Selleck, R. (1963). Fluorescent tracers for dispersion measurements. Journal of the Sanitary Engineering Division, American Society of Civil Engineers, 89(SA4), 1-21.

Fong, D. A., \& Stacey, M. T. (2003). Horizontal dispersion of a near-bed coastal plume. Journal of Fluid Mechanics, 489, 239-267.

Grant, S. B., Kim, J. H., Jones, B. H., Jenkins, S. A., Wasyl, J., \& Cudaback, C. (2005). Surf zone entrainment, along-shore transport, and human health implications of pollution from tidal outlets. Journal of Geophysical Research, 110(C10025). doi:10.1029/2004JC002401.

Guibault, G. (Ed.) (1990). Practical Fluorescence, 2nd edn. Marcel Dekker, New York.

Harris, T. F. W., Jordaan, J. M., McMurray, W. R., Verwey, C. J., \& Anderson, F. P. (1963). Mixing in the surf zone. International Journal of Air and Water Pollution, 7, 649-667.

Houghton, R. W. (1997). Lagrangian flow at the foot of a shelfbreak front using a dye tracer injected into the bottom boundary layer. Geophysical Reasearch Letters, 24(16), 2035-2038.

Inman, D. L., Tait, R. J., \& Nordstrom, C. E., (1971). Mixing in the surfzone. Journal of Geophysical Research, 26, 3493-3514.

Ledwell, J. R., Duda, T. F., Sundermeyer, M. A., \& Seim, H. E. (2004). Mixing in a coastal environment: 1. A view from dye dispersion. Journal of Geophysical Research, 109(C10013). doi:10.1029/2003JC002194.

Murthy, C. R. (1976). Horizontal diffusion charateristics in Lake Ontario. Journal of Physical Oceanography, 6, $76-84$.
Ogston, A. S., \& Sternberg, R. W. (2002). Effect of wave breaking on sediment eddy diffusivity, suspendedsediment and longshore sediment flux profiles in the surf zone. Continental Shelf Research, 22, 633-655.

Okubo, A. (1971). Oceanic diffusion diagrams. Deep Sea Research, 18, 789-802.

Omand, M. M., Feddersen, F., Clark, D. B., Franks, P. J. S., Leichter, J. J., \& Guza, R. T. (2009). The influence of bubbles and sand on chlorophyll fluorescence measurements in the surfzone. Limnology and Oceanography: Methods (2009, in press).

Pritchard, D. W. (1979). Background problems in fluorometric dye measurement in natural water. Oceans, 11, 572-582.

Pritchard, D. W., \& Carpenter, J. H. (1960). Measurements of turbulent diffusion in estuarine and inshore waters. Bulletin of the International Association of Scientific Hydrology, 20, 37-50.

Smart, P. L., \& Laidlaw, I. M. S. (1977). An evaluation of some fluorescent dyes for water tracing. Water Resources Research, 13(1), 15-33.

Stanbro, W. D., \& Pyrch, D. A. (1979). Stability of Rhodamine WT in saline waters. Water Resources Research, 15(6), 1631-1632.

Suijlen, J. M., \& Buyse, J. J. (1994). Potentials of photolytic Rhodamine WT as a large-scale water tracer assessed in a long-term experiment in the Loosdrecht Lakes. Limnology and Oceanography, 36(6), 1411-1423.

Talbot, J. W., \& Boon, M. J. (1975). The adsorption of rhodamine on to suspended sediments. ICES Journal of Marine Science, 32(2), 128-132.

Tilburg, C. E., Houghton, R. W., \& Garvine, R. W. (2007). Mixing of a dye tracer in the Delaware plume: Comparison of observations and simulations. Journal of Geophysical Research, 112(C12004). doi:10.1029/2006JC003928.

Yu, Y., Sternberg, R. W., \& Beach, R. A. (1993). Kinematics of breaking waves and associated suspended sediment in the nearshore zone. Continental Shelf Research, 13(11), 1219-1242.

Zege, E. P., Katsev, I. L., Prikhach, A. S., Gilbert, G., \& Witherspoon, N. (2006). Simple model of the optical characteristics of bubbles and sediments in seawater of the surf zone. Applied Optics, 45(25), 6577-6585. 